\title{
Effectiveness of Social Stories on Social Skills for Elementary-Aged Students with Autism: A Literature Review
}

\author{
Alexandra Christiane Daub ${ }^{1} \&$ Tonya Huber ${ }^{1, *}$ \\ ${ }^{1}$ College of Education, Anthony J. and Georgia A. Pellegrino Hall, Texas A\&M International \\ University, 5201 University Boulevard, Laredo, TX 78041, USA. \\ *Corresponding author: College of Education, Anthony J. and Georgia A. Pellegrino Hall \\ 312A, Texas A\&M International University, 5201 University Boulevard, Laredo, TX 78041, \\ USA. Tel: 1-956-326-2678. $\quad$ E-mail: tonya.huber@tamiu.edu.
} https://orcid.org/0000-0002-5078-8399

Received: September 29, 2020 Accepted: October 21, 2020 Published: November 12, 2020 doi:10.5296/ije.v12i4.17759 URL: http://dx.doi.org/10.5296/ije.v12i4.17759

\begin{abstract}
Deficits in social interactions is one of the characteristics of individuals with Autism Spectrum Disorder (ASD). There are numerous interventions that aim at establishing social skills--social stories being one of them. This review of professional literature focuses on the effectiveness of social stories on social skills of elementary-aged students with ASD. The authors identified nine peer-reviewed journal articles from the systemic review of three search engines and analyzed them through different categorizations that provide information on the methodologies used, effectiveness of social stories, the implementation of social stories, and demographic information provided on participants. Effectiveness and implementation of social stories were characterized by a large variability of findings. Effectiveness ranged from lasting behavior changes to no measurable change at all. Implementation differed regarding the mode of presentation, the use of guidelines for developing the stories, setting and reader, and other intervention strategies implemented alongside. The authors identified disparities regarding gender and racial/ethnic identity across studies, with a majority of participants being male and a lack of information concerning the racial/ethnic identity of participants. The potential gender and racial/ethnic/cultural bias needs to be addressed in further research to ensure that findings can be generalized to a larger and representative population.
\end{abstract}

Keywords: autism spectrum disorder, social skills, social stories 


\section{Introduction}

The purpose of this article is to examine literature on the effectiveness of social story interventions on social skills for elementary-aged children with autism spectrum disorder (ASD).

To review the literature with a common knowledge base of terms, three areas needed to be defined: ASD, social skills, and social stories. Table 1 provides a definition of key terms used in the article.

Table 1. Terms and Definitions

\begin{tabular}{|c|c|c|}
\hline Term & Definition & Reference \\
\hline $\begin{array}{l}\text { autism } \\
\text { spectrum } \\
\text { disorder (ASD) }\end{array}$ & $\begin{array}{l}\text { A disability characterized by deficits in two different categories. } \\
\text { Diagnosed individuals display deficits in "social communication } \\
\text { and social interaction" and show "restricted, repetitive patterns of } \\
\text { behavior, interests, or activities." The symptoms occur during the } \\
\text { early developmental period and differ in severity and the required } \\
\text { level of support. }\end{array}$ & $\begin{array}{l}\text { American Psychiatric } \\
\text { Association, 2013, } \\
\text { pp. } 50-51\end{array}$ \\
\hline $\begin{array}{l}\text { cool versus not } \\
\text { cool }(\mathrm{CNC})\end{array}$ & $\begin{array}{l}\text { A "social discrimination program in which the teacher } \\
\text { demonstrates a target behavior both the appropriate way (cool) and } \\
\text { inappropriate way (not cool)." }\end{array}$ & $\begin{array}{l}\text { Leaf et al., 2016, p. } \\
174\end{array}$ \\
\hline $\begin{array}{l}\text { photo activity } \\
\text { program }\end{array}$ & $\begin{array}{l}\text { Consists of "a series of photographs depicting the participant } \\
\text { engaging in each step of their target social behavior." }\end{array}$ & $\begin{array}{l}\text { Daneshvar et al., } \\
2019, \text { p. } 210\end{array}$ \\
\hline social skills & $\begin{array}{l}\text { Skills required to interact with peers or adults and that are } \\
\text { "necessary in natural environments such as home and school or } \\
\text { with siblings and peers." } \\
\text { For instance, initiating and maintaining conversations, offering } \\
\text { help, interacting in games, and asking and answering questions. }\end{array}$ & $\begin{array}{l}\text { Malmberg et al., } \\
2015 \text {, p. } 376 \\
\text { Karal \& Wolfe, } \\
2018 \text {,pp. } 48-49\end{array}$ \\
\hline social stories & $\begin{array}{l}\text { "Social stories are short stories that describe social situations in } \\
\text { terms of relevant social clues and often define appropriate } \\
\text { responses." }\end{array}$ & $\begin{array}{l}\text { Gray \& Garand, } \\
\text { 1993, p. } 1\end{array}$ \\
\hline $\begin{array}{l}\text { teaching } \\
\text { interaction } \\
\text { procedure }\end{array}$ & $\begin{array}{l}\text { A "systematic and interactive form of intervention that is } \\
\text { individualized to the learner and consists of six different } \\
\text { components," for instance role play. }\end{array}$ & $\begin{array}{l}\text { Kassardjian et al., } \\
2014 \text {, p. } 2330\end{array}$ \\
\hline $\begin{array}{l}\text { video modeling } \\
(\mathrm{VM})\end{array}$ & $\begin{array}{l}\text { An intervention model in which the participants watch short videos } \\
\text { of models demonstrating the target behavior. }\end{array}$ & $\begin{array}{l}\text { Malmberg et al., } \\
2015 \text {,p. } 380\end{array}$ \\
\hline
\end{tabular}


Deficits in social interactions is one of the characteristics of individuals with ASD. Social skill development is critical to avoid social isolation that may lead to social and academic difficulties (Karal \& Wolfe, 2018). Out of this reason, there are numerous interventions that aim at establishing social skills and appropriate interaction for individuals with ASD, such as pivotal response treatment, peer-mediation, or video modeling (Ozuna et al., 2015).

One of these interventions is social stories. Social stories are "short stories that describe social situations in terms of relevant social clues and often define appropriate responses" (Gray \& Garand, 1993, p. 1). Social stories were first created by Gray in 1993 and she has adjusted the guidelines multiple times since then. Stories have to meet certain defining criteria in order to be identified as a social story. Authors collect information on the audience and the social situation to create individualized stories tailored to the specific audience (Gray, n.d.). The stories consist of specific types of sentences, such as descriptive sentences describing a setting or activity step by step, directive sentences describing an expected student response, and perspective sentences describing the reactions of others' and they can be supported by visual illustrations (Gray \& Garand, 1993). Hanrahan et al. (2020) provide a social story about sharing toys written for children aged 4 to 10 years:

My name is At school I like to play with toys. My favourite toys are the trains and cars. Sometimes children can share toys, this is good. I can share by letting my friends have a go with the toy I am playing with. It makes my friends happy when I share. It is good to share. It makes __, __ and __ really happy when I share my toys. (insert teacher's name). I will try and remember to share my toys. (n.p.)

Social stories are considered an evidence-based intervention for individuals with ASD (National Autism Center, 2015) and they are frequently used by teachers and professionals (Reynhout \& Carter, 2009). However, previous research has identified various issues of concern, such as (a) questionable effectiveness with a wide range of individual outcomes (Kokina \& Kern, 2010), (b) methodological flaws in research (Leaf et al., 2015), (c) a wide range of implementation parameters (Karal \& Wolfe, 2018), and (d) limited information provided on participants (Karal \& Wolfe).

The theoretical foundation behind social story interventions is the concept of theory of mind (ToM). ToM describes the cognitive ability that enables us to "report our propositional attitudes (such states as belief, desire, hope, fear [...]) and to attribute such attitudes to others, and, more importantly, to use such postulated or observed states in the prediction and explanation of behavior" (Garfield et al., 2001, p. 495). The social impairments displayed by individuals on the autism spectrum can be explained by difficulties with ToM concepts such as understanding the perspective of others, making social situations seem unpredictable and incomprehensible (Baron-Cohen et al., 1985).

Therefore, the first approach to teaching a specific behavior that is expected in a social situation is creating an understanding of the social situation. Based on this enhanced understanding, social skills can be acquired. Social stories serve this function by describing the social situation and different perspectives included, and providing answers to the questions what, when, where, and why (Gray \& Garand, 1993). 
Even though the social story intervention was developed by Carol Gray in 1993, learning through stories and storytelling is not a new concept. On the contrary, storytelling has been part of all Indigenous cultures since the first humans inhabited the earth (Lawrence \& Paige, 2016; see also Heath, 1983; Underwood, 2002). People around the world tell and listen to stories, regardless of age, gender, or culture. "Storytelling is universal. Storytelling is one of the very few human traits that are truly universal across culture and through all of human history" (Bowman, 2018, p. 98). Stories are not only an important tool for learning about the world, a culture, and ways of living, they also serve a social function, helping to develop relationships with others within a social group. In the past, stories were used to make sense of the world and life in a community; their function was to promote social cohesion amongst individuals (Hsu, 2008).

In a "profoundly important study of the power of storytelling" (Bowman, 2018, p. 97), a neuroscientific research team conducted brain scans of a person telling a real-life story and a person listening to the recording to learn about neural mechanisms underlying the transfer of linguistic information across brains. The listener's brain activity mirrored the speaker's brain activity with temporal delays, demonstrating a speaker-listener neural coupling that only emerged during communication. "During successful communication, speakers' and listeners' brains exhibit joint, temporally coupled, response patterns" (Stephens et al., 2010, p. 14428). The implication for storytelling, a process shared by two or more individuals, is that the communication that occurs is a shared activity resulting in a transfer of information across brains (Bowman, 2018).

In this context, social stories are a variation of learning through stories and storytelling; in this specific case, stories are being used to teach social skills and social understanding to students with ASD.

\section{Methodology}

\subsection{Literature Search}

The authors conducted three literature searches, using the databases WorldCat, ERIC EBSCO, and PsycINFO to narrow to the total of nine peer-reviewed journal articles examined in this review of professional literature. The date range of the searches was from 2014 until July 2020. The literature search strategy is depicted in Table 2. The first search was conducted using WorldCat and with the search terms autism, social stories, effective, and social skills; 85 peer-reviewed articles were located. To narrow down the results and identify a "manageable corpus of entries" (Galvan \& Galvan, 2017, p. 29), the lead author examined the articles and established exclusion criteria. The second author provided a critical consideration of each step of the search analysis. 
Table 2. Audit Trail

\begin{tabular}{|c|c|c|c|c|}
\hline \multicolumn{2}{|c|}{$\begin{array}{l}\text { Database and Search } \\
\text { Terms }\end{array}$} & \multirow{2}{*}{$\begin{array}{l}\text { Exclusion Criteria } \\
\begin{array}{l}\text { No implementation of social stories/no } \\
\text { focus on effectiveness. }\end{array}\end{array}$} & \multirow{2}{*}{$\begin{array}{l}\text { Excluded } \\
\text { Articles } \\
60\end{array}$} & \multirow{2}{*}{$\begin{array}{l}\text { Remaining } \\
\text { Articles } \\
25\end{array}$} \\
\hline WorldCat & 85 results & & & \\
\hline autism AND & & Duplicate results. & 8 & 17 \\
\hline "social stories" & ND & No focus on elementary age. & 3 & 14 \\
\hline effective AND & & No focus on ASD. & 3 & 11 \\
\hline \multirow[t]{4}{*}{ “social skills" } & & No focus on social skills. & 2 & 9 \\
\hline & & Language other than English. & 1 & 8 \\
\hline & & No demographics of participants. & 1 & 7 \\
\hline & & $\begin{array}{l}\text { Literature reviews including target } \\
\text { behaviors other than social skills. }\end{array}$ & 1 & $\begin{array}{l}6 \text { relevant } \\
\text { sources }\end{array}$ \\
\hline ERIC EBSCO & 33 results & Duplicate results from WorldCat. & 10 & 23 \\
\hline “autism" AND & & $\begin{array}{l}\text { No implementation of social stories/no } \\
\text { focus on effectiveness. }\end{array}$ & 14 & 9 \\
\hline \multirow[t]{5}{*}{ "social stories" } & & No focus on elementary age. & 1 & 8 \\
\hline & & No focus on ASD. & 1 & 7 \\
\hline & & No focus on social skills. & 2 & 5 \\
\hline & & Not accessible. & 1 & 4 \\
\hline & & $\begin{array}{l}\text { Literature reviews including target } \\
\text { behaviors other than social skills. }\end{array}$ & 2 & $\begin{array}{l}2 \text { relevant } \\
\text { sources }\end{array}$ \\
\hline PsycINFO & 40 results & $\begin{array}{l}\text { Duplicate results from WorldCat and } \\
\text { ERIC EBSCO. }\end{array}$ & 27 & 13 \\
\hline \multirow{4}{*}{$\begin{array}{l}\text { “autism" AND } \\
\text { "social stories" }\end{array}$} & & No implementation of social stories/no & 7 & 6 \\
\hline & & No focus on elementary age. & 1 & 5 \\
\hline & & No focus on social skills. & 3 & 2 \\
\hline & & Language other than English. & 1 & $\begin{array}{l}1 \text { relevant } \\
\text { source }\end{array}$ \\
\hline
\end{tabular}

For 60 of the 85 articles, the authors did not implement social stories or did not focus on their effectiveness. Out of the 25 remaining studies, eight were duplicate results. Three of the remaining 17 articles focused on age groups other than elementary-school level, and another three did not focus on children diagnosed with ASD. Eleven studies remained, and five more were excluded due to the following reasons: (a) they did not focus on social skills, (b) they were in a language other than English, (c) they did not mention demographics of participants, or (e) they were literature reviews that included target behaviors other than social skills. Six relevant sources remained and were included in this review.

A second search was conducted using ERIC EBSCO. A search with the terms autism and social stories located 33 search results. Ten of the 33 results were articles already located in 
the search of WorldCat. The author applied the same exclusion criteria to the remaining 23 articles and identified two more relevant sources, a literature review by Karal and Wolfe (2018) and a study conducted in Iran by Golzari et al. (2015). A similar search with the same exclusion criteria was conducted using PsycINFO and one more relevant source was located; a pilot study by Hanrahan et al. (2020).

\subsection{Analysis}

The nine articles identified from the systemic review of three search engines were analyzed through different categorizations that provide information on the methodology used, findings of the studies regarding effectiveness of social stories, the implementation of social stories, and information provided on participants. In the findings section, similarities and differences of the research will be described based on these categories.

\section{Findings}

\subsection{Methodologies Used to Study the Effectiveness of Social Story Interventions}

An overview of the methodology and the findings on the effectiveness of social story interventions is displayed in Table 3. The nine studies included in this review can be grouped into comparative studies $(n=5)$, literature reviews $(n=2)$, and studies utilizing questionnaires as a measure of effectiveness $(n=2)$.

Five of the studies reviewed were conducted using an adapted alternating treatment design; they implemented two treatment procedures and compared their effects on the target behavior. Researchers compared social story interventions with video modeling (Acar et al., 2017; Malmberg et al., 2015), a photo activity schedule (Daneshvar et al., 2019), the teaching interaction procedure (Kassardjian et al., 2014), the cool versus not cool procedure (Leaf et al., 2016), and a time delay prompting procedure (Malmberg et al., 2015; see Table 1 for definitions and refer to Table 3 for analysis of methodology).

Two of the studies are literature reviews including a meta-analysis. Bozkurt and Vuran (2014) calculated the effect sizes using percentage of non-overlapping data (PND) scores and Karal and Wolfe (2018) used an improvement rate difference (IRD) metric. Two further research teams used a social skills questionnaire as a measure of effectiveness. Golzari et al. (2015) utilized parent-based assessment within a pre-test, post-test design and Hanrahan et al. (2020) used a teacher-based assessment within a randomized control trial (RCT) design, the first rigorous, ecologically valid RCT that investigated the effectiveness of social stories. 
Table 3. Detailed Methodology and Findings on Effectiveness of Social Stories

\begin{tabular}{|c|c|c|}
\hline Purpose & Detailed Methodology & $\begin{array}{l}\text { Findings on } \\
\text { Effectiveness }\end{array}$ \\
\hline
\end{tabular}

\section{Compare the}

effectiveness of mother-developed and delivered social stories and video modeling.

\section{Investigate if mothers can develop and implement social stories and video modeling reliably.}

\section{Investigate if effectiveness of two interventions differ.}

\section{Acar et al. (2017)}

Adapted alternating treatments design.

Phases of study:

1. Training sessions: Train mothers how to design and implement social stories and video modeling with help of a checklist.

2. Baseline: Once a day for three days; mother secured child's attention with behavior-related cue, creating occasion to show social skill; correct response defined as behavior shown within 5 seconds.

3. Intervention: Five training trials per day, 5 days per week; mother read story, asked comprehension questions, took child to setting where target skill was supposed to occur; fading process after criterion was met.

4. Maintenance: Same procedure as in baseline.

5. Generalization: Same procedure as in baseline, different setting.

Target skills: Offering assistance, asking permission to access object, identify oneself; one skill per child for each intervention.

Semi-structured interviews with mothers about goals and intervention to gather social validity data.
Social stories and video modeling almost equally effective; video modeling more efficient for two boys, stories for third boy.

All children reached $100 \%$ correct responses during social story interventions; maintained and generalized behavior with $100 \%$ accuracy.

Mothers implemented these interventions as correctly and reliable as teachers and professionals.

Social validity findings: Procedures easy to use, positive contribution to daily life, no economic burden.

\section{Bozkurt \& Vuran (2014)}

Examine and analyze studies that have used social stories to teach social skills to children with ASD.
Literature review including studies from 1991 to 2011.

Descriptive review examining 10 categories (participants, setting, research model, sentence types, maintenance, generalization, social validity, inter-observer, treatment fidelity, data collection), 32 studies included.

Meta-analysis calculating effect sizes using percentage of non-overlapping data (PND), 22 articles included.

Target skills: $56 \%$ of studies initialing verbal communication and social interaction, play skills; $31 \%$ reducing inappropriate behavior, $9 \%$ on-task behavior.
Mean PND of all studies $63.43 \%$ (questionable effectiveness), range from $0-100 \%$.

Six studies ineffective, 5 questionable, 7 effective, 4 very effective.

Stories alone are not as effective as stories with additional intervention (mean PND of $57.47 \%$ versus $65.66 \%$ ). 
Compare the efficacy of a photo activity schedule intervention and social stories.

\section{Daneshvar et al. (2019)}

Adapted alternating treatments design with an additional multiple baseline control.

Phases:

1. Baseline: Child was observed for 5 minutes during free play situation, frequency of the target social behavior was recorded, stimulus provided to evoke target behavior.

2. Intervention: Social story was read to children, comprehension questions, observation and stimulus as in baseline.

3. Maintenance: Assessed immediately after meeting criteria.

4. Generalization: Across person and setting during baseline and after acquisition of target behavior; in a nearby café.

Target skills: Greeting, sharing, commenting, initiating; one skill per child per intervention.
Examine effects of social stories on social skills of male students with ASD in Iran to evaluate efficiency of social stories.

\section{Golzari et al. (2015)}

Quasi-experimental research, pre-test and post-test design with a control group.

Parental social skill questionnaire as measure of efficacy, parents rated their children based on the areas affective understanding/ perspective-taking, initiating, responding to, and maintaining interactions.

Experimental $(n=15)$ and control group $(n=15)$. Phases:

1. Pre-test: Completion of questionnaire, assessment of participants' behavior, language, and reading level, observation of target behavior, story written based on this information.

2. Intervention: Four stories per child, story was read 3 times, if child answered questions correctly, next story was read; 16 sessions, twice a week for 2 months.

3. Post-test assessment: Parental questionnaire after 4 weeks, conduction of ANCOVA to determine if changes in rating were statistically significant.

Target skills not specified.

\section{Hanrahan et al. (2020)}

Pilot study implementing a digitally-mediated social stories randomized control trials (RCT) intervention in a school setting.
Quasi-experimental RCT between-subjects design.

Teacher-based daily and weekly questionnaires as measure of effectiveness, rating participants based on frequency and intensity of behavior, closeness to reaching story goal, understanding of social situation, anxiety.

Random allocation to intervention $(n=9)$ or control $(n=6)$ condition; teachers were blind to participants'
All four participants learned their social skills during the photo program but did not during the social story procedure; $0 \%$ of correct responses across all participants for social story interventions.
Social stories improved the social skills of experimental group. Effects were mostly evident in subscales for perceived understanding/ perspective-taking, initiating, maintaining interactions.

No effect on ability to respond to others.
Overall positive findings, significant improvements between week 1 baseline and week 6 follow-up for experimental group.

Large effects for goal-based outcome, intensity and frequency of behavior, perceived 
condition to reduce observer bias.

Weekly questionnaire filled out during baseline, intervention phase, at 6-week follow up; story sessions once a day for 2 weeks.

Target skills: Taking turns, respecting personal space, getting attention, etc. understanding measure.

No significant difference for behavior-related perceived anxiety.

\section{Karal \& Wolfe (2018)}

Examine the effectiveness of social story interventions including with whom, where, and what formats social stories have been implemented, as well as the methodological rigor of the research.
Literature review including studies from 1993 to 2015, 12 articles met inclusion criteria.

Comprehensive literature search in three phases: Key term search, title/abstract review, check articles' reference lists.

Descriptive analysis of participants, settings, format and implementation of social stories.

Calculation of effect sizes using IRD [improvement rate difference] metric as well as the SMRS [Scientific Merit Rating Scale] to evaluate methodological rigor.

Target skills: offering help, sportsmanship, maintaining/joining conversations, responding, securing attention, greeting adults, etc.

\section{Compare the teaching interaction procedure to social stories implemented in a group setting.}

Replication study of a previously conducted study from 2012.

\section{Kassardjian et al. (2014)}

Adapted alternating treatment design.

Phases:

1. Baseline: Performance probes with stimuli for the participant to engage in target skills.

2. Intervention: Performance probes, implementation of both interventions with breaks in between, 3 days a week.

3. Maintenance: Performance probe, data collected three times for two participants, twice for third participant, around 50 and 100 days after end of interventions.

Target skills: Explaining a prior cool event; three social skills randomly assigned to both interventions and a control condition, same skill for all participants.
Overall effect sizes indicate that social stories are moderately effective, but specific intervention characteristics show stronger outcomes, e.g., visual components such as photographs of participants/peers.

Four out of 12 studies reported significant increases in social skills, four moderate effect sizes, four no change for some participants.
Participants were unable to demonstrate any improvement from baseline levels on skills taught with social story ( $0 \%$ correct steps).

Teaching interaction procedure resulted in $100 \%$ of correct steps including maintenance effects.

Similar results to the ones of the original study. 
Compare cool versus not cool procedure to social stories.

\section{Leaf et al. (2016)}

Adapted alternating treatment design.

Phases:

1. Baseline: Naturalistic probe for both interventions, creating an opportunity to display target behavior.

2. Intervention: Naturalistic probes, implementation of both interventions.

3. Maintenance: Naturalistic probes.

Limited collection of generalization data.

Target skills: Interrupting appropriately, stop walking and respond when asked a question, sportsmanship (positive comments about someone playing); six social skills were randomly assigned to one of the interventions.

A series of two
experiments of treatment
comparisons.

Experiment 1:

Compare video modeling to social stories.

Experiment 2:

Compare efficacy of social stories with interventions often used in social story treatment packages (e.g. prompting).

\section{Malmberg et al. (2015)}

Experiment 1:

Multi-element design and concurrent multiple baseline design across four participants.

Phases:

1. Baseline: Assessment session with 5 min play session, observation and scoring of target behavior, partner provided opportunities for child to engage in target skill once a minute.

2. Intervention: Story read twice, assessment session, conducted once per week.

3. Maintenance: Assessed between 1 and 2 months after interventions.

4. Generalization: Assessed across unfamiliar people and new settings, during baseline and after meeting learning criterion.

Target skills: Greetings, sharing, social commenting; two skills for each participant, one for each intervention.

Experiment 2:

Social stories compared to a progressive time delay verbal prompting procedure.

Multiple baseline across participants and within participants across behaviors.

Phases:

1. Baseline: 5 opportunities to engage in target behavior during $10 \mathrm{~min}$ play session.

2. Intervention: Story read twice, opportunity to respond to stimulus immediately after.

3. Maintenance: Same as Experiment 1.

4. Generalization: Same as Experiment 1.
Participant reached 100\% of the skills taught with cool versus not cool and none of the skills taught with social stories.

Some improvement from baseline level but never more than $80 \%$ of correct steps.
All four children met criterion and learned their social behaviors during the video modeling conditions, but failed to learn their social behaviors when presented with social stories.

Prompting yielded positive results, social stories did not. 
A limitation that the studies share is the small sample size. The comparative studies include data ranging from one (Leaf et al., 2016) to four participants (Daneshvar et al., 2019; Malmberg et al., 2015). The literature reviews include a total of 12 studies (Karal \& Wolfe, 2018) and 32 studies (Bozkurt \& Vuran, 2014). However, Karal and Wolfe state that the analysis of some variables is based on a smaller sample and Bozkurt and Vuran based the meta-analysis on a subset of 22 studies that yielded PND data.

Further limitations pertain to the targeted behaviors chosen for intervention. Acar et al. (2017) state that the behaviors were assumed to be equally difficult due to an equal number of steps, however, an experimental analysis could have confirmed this assumption. Golzari et al. (2015) did not specify the targeted behavior in detail, and Kassardjian et al. (2014) report differences in assigned social skills. The behavior targeted by the social stories is considered a tact and the behavior targeted by the teaching interaction procedure a mand.

\subsubsection{Effectiveness of Comparative Studies}

Five comparative studies are included in this review and four of the research teams found social stories to be ineffective as a social skill intervention and the other intervention to be effective. Daneshvar et al. (2019) and Kassardjian et al. (2014) reported zero percent of correct responses within social story interventions (see Table 3). Leaf et al. (2016) stated that the participant reached none of the skills taught with social stories. Malmberg et al. (2015) found social stories to be ineffective in both conducted experiments.

Acar et al. (2017) compared social stories and video modeling and found both interventions to be effective. The authors state that "consistent efficiency findings in favor of one intervention could not be determined" (p. 221). Video modeling was more efficient for two boys and social stories for the third boy.

\subsubsection{Effectiveness of Literature Reviews}

The research teams of both literature reviews reach similar conclusion about the effectiveness of social story interventions, reporting moderate overall effectiveness with a wide range of individual effect sizes. Karal and Wolfe (2018) calculated a mean IRD of 0.62 (moderate effectiveness), with four of the 12 studies reporting significant increases in social skills, four reporting moderate effect sizes, and four showing no change for some participants (p. 53). Bozkurt and Vuran (2014) calculated a mean PND of 63.43\% (questionable effectiveness) with a range from 0 to $100 \%$ and four very effective studies, seven effective studies, five questionable studies, and six ineffective ones (p. 1885).

It should be noted that of the 12 studies reviewed by Karal and Wolfe (2018), ten were also included in Bozkurt and Vuran's (2014) descriptive review, and eight of them were part of their meta-analysis. The remaining two studies were published outside of the date range in which Bozkurt and Vuran searched.

Both literature reviews categorized four studies to be very effective. However, two of the four studies that Bozkurt and Vuran (2014) categorized as very effective did not focus on social skills but the reduction of inappropriate behavior and tantrums. Even though the study title 
mentions social skills as targeted behavior, $31 \%$ of included studies aim at reducing inappropriate behavior and $9 \%$ at increasing on-task behavior. The remaining two studies categorized as very effective did not include maintenance or generalization data. One of them (i.e., Barry \& Burlew, 2004) was therefore classified as initial evidence with more rigorous research needed by Karal and Wolfe (2018, p. 52). Karal and Wolfe categorized four studies as showing significant increases in social skills. Three of them showed sufficient scientific rigor (i.e., Sansotti \& Powell-Smith, 2008; Scattone, 2008; Thiemann \& Goldstein, 2001). An aspect these three studies have in common is the involvement of digital media; the social stories were read by the students themselves and were presented on a computer or as a video or included video feedback.

Interestingly, one of the studies that showed significant increases in social skills (i.e., Thiemann \& Goldstein, 2001; mean IRD of 0.87) according to Karal and Wolfe (2018), was rated as having questionable intervention effectiveness (mean PND of 58\%) and ineffective maintenance and generalization effectiveness (mean PND of $34 \%$ and $22 \%$ ) by Bozkurt and Vuran (2014), revealing the significance of taking into account the method of data analysis when making statements about an intervention's effectiveness.

\subsubsection{Effectiveness of Studies Utilizing Questionnaires}

Both studies utilizing social skills questionnaires report overall positive findings. Based on a parental perspective, Golzari et al. (2015) mentions positive effects on the participants' understanding/perspective-taking and the abilities to initiate and maintain interactions; no effect on the ability to respond to others was found. Hanrahan et al. (2020) reports significant improvements between baseline in week one and the 6-week follow up for the experimental group based on class teachers' perspectives. The researchers found large effects on the goal-based outcome, intensity and frequency of the behavior, and on perceived understanding. No significant difference for behavior-related anxiety was reported. The efficacy of social story interventions was based on parental and teachers' perspective, no direct data from participants were included.

\subsection{Implementation of Social Stories}

The researchers' implementation of social stories is characterized by a large variety regarding the mode of presentation, the use of Gray's guidelines, setting and reader, and other intervention strategies implemented alongside (see Table 4). Researchers chose different modes of presentation with varying supportive visuals, such as clipart pictures or photographs of the educational environment, peers, or the participant; some stories were presented in a written format only. Stories were presented in a book format, on a clipboard, digitally on a computer or using PowerPoint. Bozkurt and Vuran (2014) reviewed a study that utilized a musical story presentation and Hanrahan et al. (2020) utilized a story application developed by members of their research team to present the story on an iPad.

The range of interventions implemented alongside the social story interventions is similar, spanning from no secondary interventions to using video models. All research teams except for two (Bozkurt \& Vuran, 2014; Hanrahan et al., 2020) mention the use of comprehension 
questions after reading the story to the child. Karal and Wolfe (2018) reported that 7 out of 12 studies included comprehension questions. Additional intervention strategies were prompting (Acar et al., 2017) and reinforcement through social praise (Daneshvar et al., 2019) or a token system (Kassardjian et al., 2014). The authors of the literature reviews reveal an even larger variety of strategies, including video modeling, physical prompting, video feedback, and peer training (see Table 4).

Table 4. Implementation of Social Stories

\begin{tabular}{|c|c|c|c|}
\hline $\begin{array}{l}\text { Mode of } \\
\text { Presentation }\end{array}$ & Gray's Guidelines & $\begin{array}{l}\text { Setting and } \\
\text { Reader }\end{array}$ & $\begin{array}{l}\text { Implementation } \\
\text { along with }\end{array}$ \\
\hline \multicolumn{4}{|c|}{ Acar et al. (2017) } \\
\hline $\begin{array}{l}\text { Content } \\
\text { appropriate } \\
\text { pictures. }\end{array}$ & N/A & $\begin{array}{l}\text { Children's } \\
\text { home; } \\
\text { Mothers. }\end{array}$ & $\begin{array}{l}\text { Prompting: Verbal prompt when } \\
\text { incorrect responses were provided } \\
\text { after reading the story } 3 \text { times. } \\
\text { Comprehension questions: } 5 \text {. }\end{array}$ \\
\hline \multicolumn{4}{|c|}{ Bozkurt \& Vuran (2014) } \\
\hline $\begin{array}{l}\text { Story alone in } \\
27.27 \% \text { of } \\
\text { studies. } \\
\text { Others: } \\
\text { Photography, } \\
\text { visual support, } \\
\text { computer } \\
\text { format, music. }\end{array}$ & $\begin{array}{l}\text { Gray not specified. } \\
\text { High frequency of } \\
\text { descriptive, directive, } \\
\text { reflective sentences; } \\
\text { control affirmative, } \\
\text { cooperative sentences } \\
\text { more rarely. }\end{array}$ & $\begin{array}{l}\text { School/ } \\
\text { institution, } \\
\text { home, multiple } \\
\text { settings; } \\
\text { Researchers, } \\
\text { teachers, } \\
\text { parents, } \\
\text { para-professiona } \\
\text { ls, mother, } \\
\text { therapist. }\end{array}$ & $\begin{array}{l}72 \% \text { of } 22 \text { studies implemented with } \\
\text { additional interventions: video } \\
\text { model, verbal and physical } \\
\text { prompting, reinforcement, music, } \\
\text { video feedback, token system. }\end{array}$ \\
\hline
\end{tabular}

Daneshvar et al. (2019)

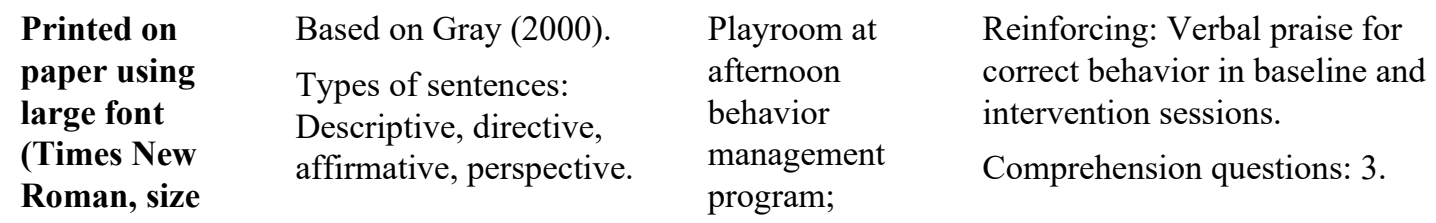

\section{8).}

Visuals not mentioned.
Researcher,

1 participant read story out

loud.

Golzari et al. (2015)

$\begin{array}{ll}\begin{array}{l}\text { PowerPoint, } \\ \text { printed }\end{array} & \text { Gray } 2000 . \\ \text { materials with } & \text { Each story 5-10 } \\ \text { colored } & \text { descriptive, perspective, } \\ \text { pictures. } & \text { directive sentences, } \\ & \text { written in third person. }\end{array}$



ipad, personalized photos, "Stories
Online For
Autism" App

Hanrahan et al. (2020)

Gray 2010.

Classroom;

None mentioned.

Criteria provided in appendix.
Researcher.

\section{Karal \& Wolfe (2018) Total of 12 studies}

$\begin{array}{ll}\text { 7 with clipart/ } & \text { Based on Gray (between } \\ \text { pictures, } & \text { 1993 and 2010), indicated } \\ \text { by 10 studies. } \\ \text { computer-prese } & \text { Types of sentences: } \\ \text { nted, } & \begin{array}{l}\text { Descriptive, coaching and } \\ \text { perspective sentences in }\end{array} \\ \mathbf{1} \text { with photos of } & \text { all stories; control, } \\ \text { participants/ } & \text { cooperative and } \\ \text { peers/ } & \text { affirmative sentences less } \\ \text { classroom, } & \text { frequent. }\end{array}$

10 school settings, 2 medical centers;

4 teachers, 2 researchers, 6 students.
Prompting: Mentioned in 6 studies.

Reinforcing: Mentioned in 1 study.

Comprehension questions:

Mentioned in 7 studies.

Other strategies mentioned:

Meyer-Johnson picture symbols, peer training, corrective feedback, video feedback.

1 written only.

Written in a
book format.
Pages included
pictures or
icons.
Presentation in
group setting.

\section{Kassardjian et al. (2014)}

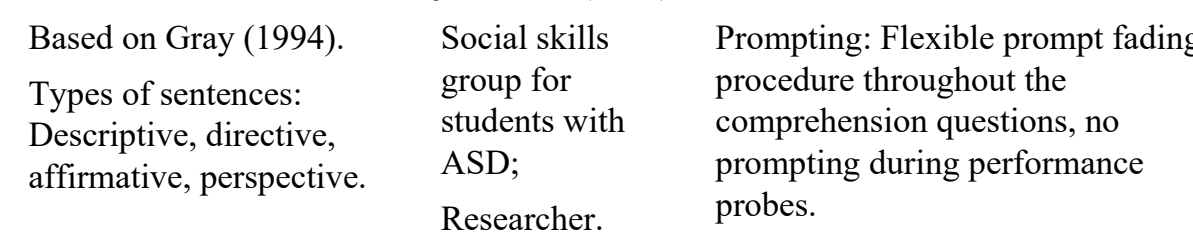

Reinforcing: Token economy across both interventions.

Comprehension questions: 4.

\section{Leaf et al. (2016)}

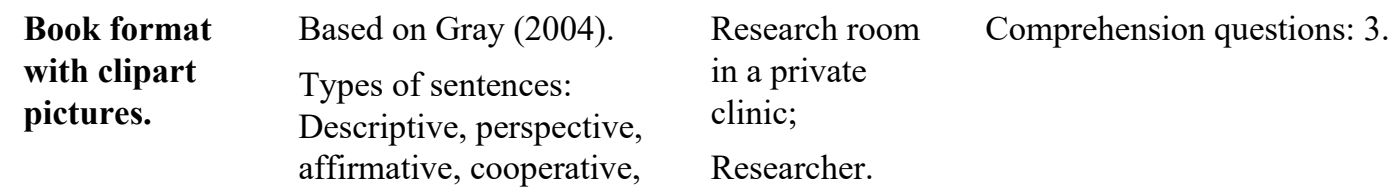
control, directive.

\section{Malmberg et al. (2015) Experiment 1}
Printed on paper with Based on Gray (2004).

\section{Behavior} Comprehension question: 1 . clipart picture.
Types of sentences: therapy clinic;
Times New Descriptive, directive, Researcher.
Roman 16-24, presented on a clipboard. affirmative, perspective.

\section{Malmberg et al. (2015) Experiment 2}

$\begin{array}{llll}\begin{array}{l}\text { Printed on } \\ \text { paper with } \\ \text { clipart picture. }\end{array} & \begin{array}{l}\text { Based on Gray (1993). } \\ \text { Types of sentences: }\end{array} & \begin{array}{l}\text { Behavior } \\ \text { therapy clinic; } \\ \text { Descriptive, directive, }\end{array} & \text { Researcher. } \\ & \text { affirmative, perspective. } & \end{array}$


Interventions took place in different settings, ranging from home to school and clinical settings. One research team read the stories in a group setting and all other researchers worked with the children individually. The stories were read by mothers, teachers, researchers, or the child him- or herself (see Table 4).

Acar et al. (2017) was the only study that examined mother-delivered social stories. Their study is one of the few studies in which a parent both developed and implemented the social story. The "mothers implemented these interventions as correctly and reliable as teachers and professionals" (p. 222) and with a high treatment integrity.

\subsection{Demographics of Participants}

The authors of all nine articles provided information on age and gender of participants (see Table 5). The ages ranged from 3 to 13 years. Karal and Wolfe (2018) reviewed studies with the age range 3 to 13 . Their study was reviewed despite the fact that non-elementary aged students were included because the majority of participants (26 out of 30) was within the required elementary age range.

Table 5. Demographics of Participants

\begin{tabular}{|c|c|c|c|}
\hline Age and Gender & $\begin{array}{l}\text { Racial/ } \\
\text { Ethnic } \\
\text { Identity }\end{array}$ & Standardized Data & Social Skills \\
\hline \multicolumn{4}{|c|}{ Acar et al. (2017) } \\
\hline \multirow[t]{4}{*}{3 males. } & \multirow{4}{*}{$\begin{array}{l}\text { Participants } \\
\text { are from } \\
\text { Turkey. }\end{array}$} & $\begin{array}{l}\text { Three participants diagnosed as } \\
\text { having ASD by child } \\
\text { psychiatrists in public hospitals. }\end{array}$ & $\begin{array}{l}\text { Participant 1: Expressive verbal } \\
\text { skills, could read and write, could } \\
\text { use greeting words with } \\
\text { prompting. }\end{array}$ \\
\hline & & & $\begin{array}{l}\text { Participant 2: Receptive and } \\
\text { expressive language skills, } \\
\text { age-appropriate social skills such } \\
\text { as greeting. }\end{array}$ \\
\hline & & & $\begin{array}{l}\text { Participant 3: Reading and } \\
\text { writing level below his peers, } \\
\text { limited problem-solving skills/ } \\
\text { understanding of cause-effect } \\
\text { relationship. }\end{array}$ \\
\hline & & & $\begin{array}{l}\text { None of the boys initiated or } \\
\text { maintained social interactions } \\
\text { with peers/adults. }\end{array}$ \\
\hline \multicolumn{4}{|c|}{ Bozkurt \& Vuran (2014) } \\
\hline $\begin{array}{l}31 \% 0-6 \text { years, } \\
57 \% 7-12\end{array}$ & $\mathrm{~N} / \mathrm{A}$ & $\begin{array}{l}70 \text { participants with ASD: } \\
\text { (Discrepancy in total number.) }\end{array}$ & $\mathrm{N} / \mathrm{A}$ \\
\hline $6 \% 12-15$ & & $85 \%$ autism, $6 \%$ Asperger's, $9 \%$ & \\
\hline $\begin{array}{l}65 \text { males, } \\
6 \text { females. }\end{array}$ & & $\begin{array}{l}\text { Pervasive Developmental } \\
\text { Disorder-Not Otherwise }\end{array}$ & \\
\hline
\end{tabular}




\begin{tabular}{|c|c|c|}
\hline $\begin{array}{l}\text { Participant 1: } 5 \\
\text { years, }\end{array}$ & $\begin{array}{l}\text { Chinese } \\
\text { American, }\end{array}$ & $\begin{array}{l}\text { Four participants diagnosed with } \\
\text { ASD based on DSM-5. }\end{array}$ \\
\hline 11 months. & Hispanic, & Mental age (MA) determined \\
\hline Participant 2: & Caucasian, & using Peabody Picture \\
\hline 6 years, & Filipina-Am & Vocabulary Test- Revised \\
\hline & erican. & litio \\
\hline 7 month & & Participant 1: \\
\hline Participant 3: & & MA of 3 years, 10 months. \\
\hline 8 years, & & Participant 2: \\
\hline 3 months. & & MA of 1 year, 11 months. \\
\hline Participant 4: & & Participant 3: \\
\hline 10 years, & & MA of 6 years, 1 month. \\
\hline 5 months. & & Participant 4: \\
\hline & & MA of 2 years, 5 months. \\
\hline
\end{tabular}

Significant social skills deficits (based on observations and Vineland Adaptive Behavior Scale).

Participant 1: Does not initiate social interaction and rarely responds to others.

Participant 2: Often plays alone, rarely initiates social interaction, does not spontaneously share or take turns with others.

Participant 3: Interacts with others when prompted but often not appropriately, frequently asks others to leave her alone.

Participant 4: Does not initiate to others or respond to social bids, does not take turns or share.

2 males,

2 females.

\begin{tabular}{|c|c|c|c|}
\hline \multicolumn{4}{|c|}{ Golzari et al. (2015) } \\
\hline 6-12-year-old. & $\mathrm{N} / \mathrm{A}$ & Label of ASD only. & $\mathrm{N} / \mathrm{A}$ \\
\hline 30 males. & $\begin{array}{l}\text { Study } \\
\text { conducted in } \\
\text { Shiraz City, } \\
\text { Iran. }\end{array}$ & & \\
\hline \multicolumn{4}{|c|}{ Hanrahan et al. (2020) } \\
\hline 4-10 years. & $\begin{array}{l}14 \text { White } \\
\text { British, }\end{array}$ & $\begin{array}{l}15 \text { participants with ASD } \\
\text { diagnosis from a clinician, no }\end{array}$ & $\begin{array}{l}\text { Exclusion of students who were } \\
\text { minimally verbal. }\end{array}$ \\
\hline $\begin{array}{l}14 \text { males, } \\
1 \text { female. }\end{array}$ & $\begin{array}{l}1 \text { British } \\
\text { Asian. }\end{array}$ & co-occurring diagnosis. & \\
\hline \multicolumn{4}{|c|}{ Karal \& Wolfe (2018) Total of 12 studies } \\
\hline 2 at age 3 , & \multirow[t]{12}{*}{$\mathrm{N} / \mathrm{A}$} & 30 participants with ASD: & Communication skills ranged \\
\hline 1 at age 5 & & 3 severe autism, & $\begin{array}{l}\text { from non-verbal to verbal } \\
\text { individuals }\end{array}$ \\
\hline 6 at age 6 , & & 5 mild to moderate autism, & \multirow{10}{*}{$\begin{array}{l}\text { Most of the students who were } \\
\text { capable of speech and able to } \\
\text { communicate verbally had } \\
\text { difficulty with conversation skills } \\
\text { and had impaired social } \\
\text { communication skills. }\end{array}$} \\
\hline 2 at age 7 & & 3 Asperger's syndrome. & \\
\hline 7 at age 8 , & & Diagnosis based on DSM-IV. & \\
\hline 4 at age 9 & & $\begin{array}{l}6 \text { studies provided standardized } \\
\text { data about participants, mostly }\end{array}$ & \\
\hline 4 at age 10 & & diagnostic labels of autism or & \\
\hline 2 at age 11, & & ASD only. & \\
\hline 1 at age 12 & & & \\
\hline 1 at age 13. & & & \\
\hline 27 males, & & & \\
\hline 3 females. & & & \\
\hline
\end{tabular}




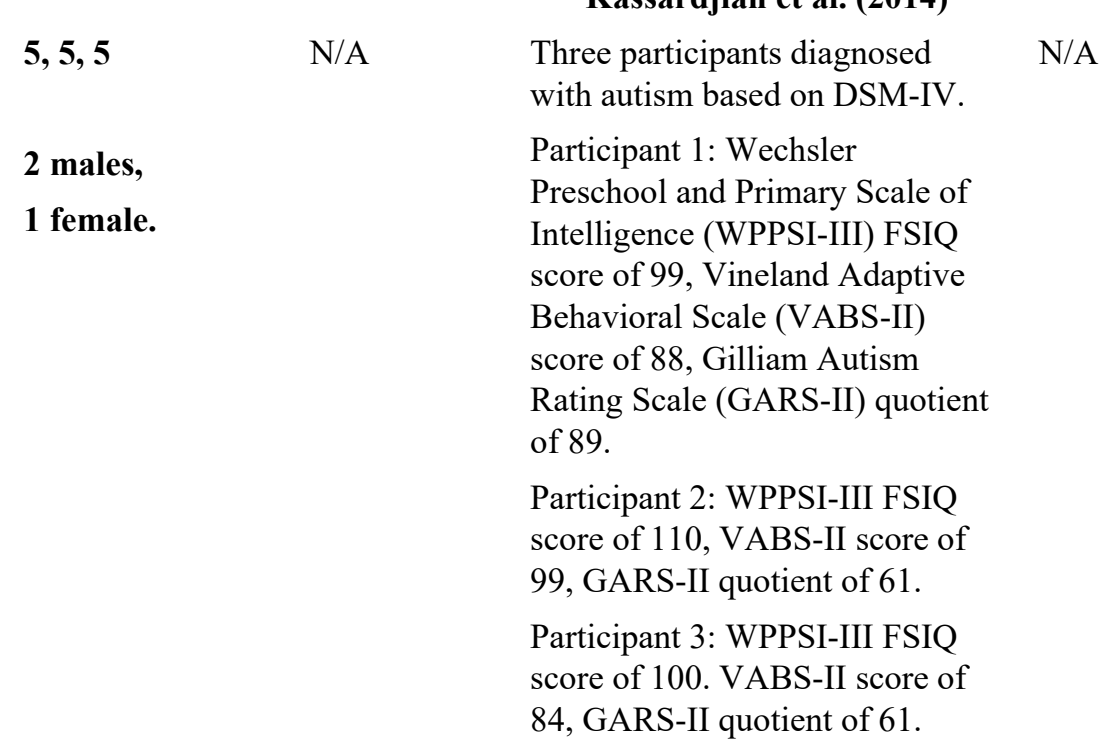

7

1 male.

Upper
middle class
family.

Caucasian.

Full scale IQ score of 122 (ab
average), Vineland adaptive
behavior score of 94 (adequa Social Skills Improvement System Standard Score of 78 (7\%), Social Responsiveness Standard Score of 56 (normal range for ASD),

Peabody Picture Vocabulary Receptive Score of 121 (92\%),

Expressive One Word Score of 137 (99\%) (p. 175).
Displayed basic social behaviors (e.g., joint attention, greetings, parallel play) in his natural environment, he seldom independently interacted with his peers.

Considered high functioning by parents and teachers due to spontaneous language throughout the day.

\section{Malmberg et al. (2015) Experiment 1}

$\begin{array}{ll}\text { Participant 1:6 } & \text { Hispanic, } \\ \text { years, } & \text { Caucasian, } \\ \text { 4 months. } & \text { Filipino, } \\ \text { Participant 2: } & \text { Caucasian. } \\ \text { 6 years, } & \\ \text { 7 months. } & \end{array}$

Participant 3:

6 years,

10 months.

Participant 4: 8

years,

9 months.

3 males,

1 female.
Four participants diagnosed with ASD based on DSM-5.

Participant 1: Peabody Picture Vocabulary Test (PPVT)-II score of 64, Vineland Adaptive Behavior Scale score of 91.

Participant 2: PPVT score of 79, Vineland score of 85.

Participant 3: PPVT score of 68, Vineland score of 78.

Participant 4: PPVT score of 87 , Vineland score of 75.
Participant 1: Poor eye contact, echolalia, responds to social bids but does not initiate.

Participant 2: Rarely initiates social interaction with others, frequent eye contact, often plays interactive games appropriately with prompting.

Participant 3: Responds to name with eye contact, frequently initiates social interactions, echolalia.

Participant 4: Fleeting eye contact, limited and atypical social initiations, no engaging in social interaction. 


\begin{tabular}{|c|c|c|c|}
\hline \multicolumn{4}{|c|}{ Malmberg et al. (2015) Experiment 2} \\
\hline $\begin{array}{l}\text { Participant 1: } \\
6 \text { years, }\end{array}$ & $\mathrm{N} / \mathrm{A}$ & $\begin{array}{l}\text { Two participants diagnosed with } \\
\text { ASD based on DSM-5. }\end{array}$ & $\begin{array}{l}\text { Participant 1: Extensive vocal } \\
\text { repertoire, echolalia. }\end{array}$ \\
\hline 5 months. & & $\begin{array}{l}\text { Participant 1: PPVT- } 4 \text { of } 81 \text {, } \\
\text { Vineland scores of } 88 \text { for } \\
\text { communication and } 58 \text { for } \\
\text { socialization. }\end{array}$ & $\begin{array}{l}\text { Participant 2: Speaks in full } \\
\text { sentences, high levels of vocal } \\
\text { stereotypy. }\end{array}$ \\
\hline $\begin{array}{l}8 \text { years, } \\
11 \text { months. }\end{array}$ & & $\begin{array}{l}\text { Participant } 2 \text { : PPVT- } 4 \text { of } 75 \text {, } \\
\text { Vineland scores of } 91 \text { for } \\
\text { communication and } 56 \text { for } \\
\text { socialization. }\end{array}$ & \\
\hline
\end{tabular}

Adding all participants of the reviewed studies, data of a total of 136 participants were included in this review, taking into consideration the participants included in both literature reviews. Twelve of the participants $(8.8 \%)$ were female and the remaining 124 were male (91.2\%). For 24 out of the 136 participants, researchers reported the children's racial/ethnic identity. The research teams providing this information were Daneshvar et al. (2019), Hanrahan et al. (2020), Leaf et al. (2016), and Malmberg et al. (2015) in one of the experiments.

The authors use the term racial/ethnic identity as opposed to the single terms race or ethnicity in accordance with the American Psychological Association's (APA, 2020) bias-free language guidelines. APA (2020) recommends "rereading your work for preconceptions about groups of people" (p. 131). Since researchers of reviewed studies did not specify how information on participants' racial or ethnic identity was collected (i.e., through self-identification or researchers' attribution), the term racial/ethnic identity aims at avoiding preconceptions.

Further information on participants' demographics was provided in terms of standardized test data and brief verbal descriptions of the children's social skills. The authors of five studies briefly described the participants' social skills (refer to Table 5 for details). Four research teams supported the participants' diagnosis through providing standardized test data (Daneshvar et al., 2019; Kassardjian et al., 2014; Leaf et al., 2016; Malmberg et al., 2015), ranging from scores of one test (Daneshvar et al.) to scores of as many as six tests (Leaf et al.). Karal and Wolfe (2018) mentioned six studies that reported standardized data, stating that "in most instances, participants were given diagnostic labels of only either autism or ASD" (p. 47). The study conducted by Golzari et al. (2015) is the one that reports the least information, only the participants' age range and a label of ASD is given.

\section{Discussion}

The purpose of this article is to examine professional literature on the effectiveness of social stories as a social skills intervention for elementary-aged children with ASD. Nine articles met the inclusion criteria and were analyzed through different table categorizations providing 
information on methodology, findings on effectiveness, the implementation of social stories, and information provided on participants.

The findings of this systemic review of literature are consistent with previous research that mentions a large variability of findings on effectiveness and implementation of social stories (Bozkurt \& Vuran, 2014; Karal \& Wolfe, 2018; Kokina \& Kern, 2010). The social stories were based on different guidelines, constructed with different sentence types, presented differently and in varying setting; read by researchers, mothers, teachers, or the students themselves, and implemented along with prompting, reinforcement, a token system, and comprehension questions.

The findings on effectiveness are also characterized by a wide range of results. Acar et al. (2017) is the only research team that reports positive findings using an adapted alternating treatments design. The three participants reached $100 \%$ of correct responses during the interventions and maintained and generalized the behavior with 100\% accuracy (maintenance data with two participants only). The other research teams conducting a comparative study (Daneshvar et al., 2019; Kassardjian et al., 2014; Leaf et al., 2016; Malmberg et al., 2015) report no behavior change for the social skill targeted by the social story intervention.

The two studies measuring social story effectiveness with a parent- or teacher-based social skills questionnaire report positive findings. Based on the parents' perceptions, the children's understanding/perspective-taking and ability to initiate and maintain interactions improved (Golzari et al., 2015) and, based on teachers' perception, the children reached the story goal, intensity and frequency of the behavior decreased, and understanding improved (Hanrahan et al., 2020).

The differences in the creation and implementation of the social stories pose a challenge to identifying reasons why some researchers found social stories to be an effective intervention and some reported no behavior change at all. Malmberg et al. (2015) expressed this accurately: "What is especially needed is a pure component analysis of social stories treatment packages to determine the exact functional variables responsible for behavior change" (p. 386).

However, three interesting approaches can be derived from the similarities and differences of the studies that were reviewed, (a) the role of digital media, (b) active student engagement, and (c) the role of parent-developed and implemented social stories. Karal and Wolfe (2018) reviewed four studies that reported significant increases in social interactions and these four studies included visual components that differed from the other studies (i.e., photographs of participants, peers, and the environment; computer presentation; and video feedback). The authors mention the nature of these visuals and the influence of digital media as possible reasons for the significant increases in social skills. Hanrahan et al. (2020) presented their social stories using an autism story application developed by members of the research team, combining traditional oral storytelling with individualized digital images, graphics, and sounds delivered on an iPad. They describe benefits of digitally-mediated social stories: "Computers can provide a more consistent and structured environment for the story, enabling repetition and direct feedback, and can offer the child more control over the learning 
experience" (n. p.).

Utilizing story applications for social story delivery allows for illustrating the stories with personalized pictures and encourages active student involvement with the story. The story can stay with the child as a permanent reminder and can be used independently of adult prompts (Kokina \& Kern, 2010).

Another promising approach are parent-developed and delivered stories. Acar et al. (2017) was the only comparative study in this review that reported evidence for positive effects of social story interventions on social skills and the most remarkable difference between their research and the other studies is the delivery by a parent and in a home setting. The mothers developed social stories with the support of a checklist and implemented them independently with a high treatment fidelity. They found the intervention to be easy to use, the learning outcomes significant, and they enjoyed working with and teaching their children. The sample of this review is too restricted to demonstrate a connection between these variables but drawing the connection identifies a needed approach for further research.

Analyzing the information provided on participants' demographics revealed two gaps, regarding gender and racial/ethnic identity. A large amount of research exists on the topic of effectiveness of social story interventions for individuals with ASD. However, when focusing on specific groups of students, samples of participants decreased in number. Despite the use of specific search terms, a search with the database WorldCat identified 85 sources. This large number of sources might suggest a large number of participants; however, after applying the exclusion criteria, only six relevant sources remained (see Table 2). Additional searches with the databases ERIC EBSCO and PsycINFO located only three more studies that focused on social story interventions on social skills and the relevant participant population of this article, elementary-aged students with ASD. A closer analysis of the studies further narrowed down the sample size of specific participant groups. Out of a total of 136 participants, only twelve children were female and racial/ethnic identity was mentioned for only 24 of them. The racial/ethnic identities included four Caucasian students, 14 White British students, two Hispanics, two Filipinos and Filipinas, one Chinese American student, and one British Asian (see Table 5).

These two gaps, few female participants in autism research and sparse information on participants' racial/ethnic identity, are consistent with prior research. Garwood and Van Loan (2019) analyzed literature reviews and meta-analyses that included social stories for students with social, emotional, and behavioral disorders. The 16 reviews and meta-analyses they analyzed included a total of 128 students. Out of these 128 participants, only 19 were female $(14.72 \%)$ and the majority of studies did not include information on students' racial/ethnic identity.

Furthermore, many studies provide a diagnostic label of ASD only (Karal \& Wolfe, 2018) without giving further information regarding social or communication skills (Bozkurt \& Vuran, 2014; Golzari et al., 2015; Hanrahan et al., 2020).

The gap in diagnosis data, as well as the small numbers of female participants and studies 
including racial/ethnic identity data, raise questions regarding the generalization to a wide population of students, especially since sample sizes of the studies were small to begin with. The variety of research findings for social story interventions indicates that there is more research needed to identify specific parameters that are related to effectiveness of social stories. More detailed background information on the participants is needed to identify the target population of social story interventions. Garwood and Van Loan (2019) state that "external validity could be improved by including rich descriptions of participants and procedures" (pp. 144-145).

It should be noted that the overrepresentation of male participants in this review might be connected to the prevalence rates of ASD. The Center for Disease Control and Prevention's Autism and Developmental Disabilities Monitoring Network collected prevalence data from health and special education records among 8-year-olds for the year 2016. They report that ASD is 4.3 times as prevalent among boys as among girls, affecting 1 in 34 boys and 1 in 145 girls (Matthew et al., 2020). However, researchers have noted concerns that prevalence rates and sex ratio might be impacted by gender-biased diagnostic criteria and screening tools (Haney, 2016). Screening tools are based on a description of a male autistic phenotype, making their value for identifying and diagnosing females with ASD questionable (Beggiato et al., 2016; Haney, 2016). For instance, research examining gender differences in ASD symptoms identified greater motor deficits and less communication impairments among high-functioning females with ASD (Matheis et al., 2019). There is a need to adjust screening and assessment tools to reduce the risk for females on the spectrum to be overlooked and remain undiagnosed (Loomes et al., 2017). Even if the gender disparity in research is due to larger prevalence rates among males, the female phenotype of ASD is not yet well researched or understood (Matheis et al., 2019). This review confirms the concerns of a gender bias, with only 12 of 124 participants $(8.8 \%)$ being female.

In addition to the gender bias, findings also suggest a racial/ethnic bias. For only 24 out of 136 participants, racial/ethnic identity is mentioned and 18 out of the 24 were White, suggesting a male White autistic phenotype as the common participant sample. To reduce bias in research, researchers who want to generalize the study results to students overall should assess and report if the participant sample they studied is different from the target population (APA, 2020). Therefore, the lack of information regarding ASD diagnosis and racial/ethnic identity constitutes an obstacle for meaningful interpretation of the findings. Research on essential distinctions in ethnic/cultural ways of telling, sharing, and interpreting stories has expanded the knowledge base concerning incorporating storytelling in school culture to assist educators in creating meaningful continuity between home and school culture in the use and process of storytelling as well as with appropriate content (Azuma, 1994; Delgado-Gaitan, 1987; Heath, 1982; Ogbu, 1982; Suina \& Smolkin, 1994; Underwood, 2002; Windchief \& San Pedro, 2019). To conduct research on using stories to teach in a vacuum of the cultural content and context of stories within and between cultures is to mislead and, more pointedly, miseducate (Eisner, 1994, p. 37). If ethnic/racial/cultural demographics of people are not included in the research, making assumptions and generalizing the study findings to a larger population is questionable. 


\section{Summary}

Taking all variables into consideration, research paints a rather heterogenous image of the effectiveness of social stories as a social skills intervention without reaching an agreement of which parameters are responsible for behavior changes. At this point, it could be helpful to take a step back and regard social stories in the greater context of learning through stories and storytelling. In one of the first articles, Gray and Garand (1993) state that "writing social stories is an art not a science .... Creativity matched with an individualized understanding of a student and situation are among the most valuable ingredients for effective social stories" ( $p$. 5). Stories have been told ever since human history began; they were used to make sense of the world, to pass on the knowledge to the next generation, and to promote social cohesion among individuals (Hsu, 2008). Likewise, social stories provide social information on a target behavior to help students with ASD make sense of a social situation. Additionally, perspective sentences describe the perspective and response of others, promoting the acquisition of ToM. Garfield et al. (2001) argue that the acquisition of ToM "is essentially social in character, and that the body of knowledge represented by ToM is inextricably bound up with broader knowledge about persons and their lives" (p. 496). The content of social stories as well as the shared experience of reading and telling the story can be a step towards the acquisition of ToM.

Placing social stories in this context can promote a shift in the way social stories are perceived. "Gray (2004) emphasized that Social Stories are in no way a tool for behavior change; rather, the premise of the intervention is that better social understanding will lead to improvement in behavior and social functioning" (Kokina \& Kern, 2010, pp. 812-813). Understanding a social situation is necessary to display a social skill, however, enhanced understanding and social information does not necessarily translate to being able to demonstrate the skill. Rather, social stories should be considered the first step in teaching a social behavior. A student may understand a social concept but may lack the skills to apply this knowledge and a different intervention might be necessary for the student to display the behavior (Kokina \& Kern). This notion is supported by the wide range of additional intervention strategies that were implemented along with social stories (see Table 4).

This context shifts social stories' learning outcome from demonstrating a target behavior to enhanced social understanding, an outcome that cannot be measured in a quantitative scientific way. It may be that this is the reason why social stories were considered ineffective by a majority of the researchers that measured effectiveness with the dependent variable of percentage of correct responses. Based on parents' and teachers' perspectives, social stories were reported to increase perceived understanding/perspective-taking abilities of the students (Golzari et al., 2015; Hanrahan et al., 2020).

\section{References}

Acar, C., Tekin-Iftar, E., \& Yikmis, A. (2017). Effects of mother-delivered social stories and video modeling in teaching social skills to children with autism spectrum disorders. The
Journal
of
Special
Education,
$50(4)$
215-226. 
https://doi.org/10.1177/0022466916649164

American Psychiatric Association. (2013). Diagnostic and statistical manual of mental disorders: DSM-5 (5 $5^{\text {th }}$ ed.). American Psychiatric Association. https://doi.org/10.1176/appi.books.9780890425596

American Psychological Association. (2020). Publication manual of the American Psychological Association ( th $^{\text {ed. }}$ ) https://doi.org/10.1037/0000165-000

Azuma, H. (1994). Two modes of cognitive socialization in Japan and the United States. In Patricia M., Greenfield \& Rodney R. Cocking (Eds.), Cross-cultural roots of minority child development (pp. 275-284). Lawrence Erlbaum Associates.

Baron-Cohen, S., Leslie, A. M., \& Frith, U. (1985). Does the autistic child have a "theory of mind"? Cognition, 21(1), 37-46. https://doi.org/10.1016/0010-0277(85)90022-8

Beggiato, A., Peyre, H., Maruani, A., Scheid, I., Rastam, M., Amsellem, F., Gillberg, C. I., Leboyer, M., Bourgeron, T., Gillberg, C., \& Delorme, R. (2017). Gender differences in autism spectrum disorders: Divergence among specific core symptoms. Autism Research: Official Journal of the International Society for Autism Research, 10(4), 680-689. https://doi.org/10.1002/aur.1715

Bowman, R. F. (2018). Teaching and learning in a storytelling culture. The Clearing House: A Journal of Educational Strategies, Issues and Ideas, 91(3), 97-102. https://doi.org/10.1080/00098655.2017.1373547

Bozkurt, S., \& Vuran, S. (2014). An analysis of the use of social stories in teaching social skills to children with autism spectrum disorders. Educational Sciences: Theory and Practice, 14(5), 1875-1892. https://eric.ed.gov/?id=EJ1050428

Daneshvar, S. D., Charlop, M. H., \& Malmberg, D. B. (2019). A treatment comparison study of a photo activity schedule and social stories for teaching social skills to children with autism spectrum disorder: Brief report. Developmental Neurorehabilitation, 22(3), 209-214. https://doi.org/10.1080/17518423.2018.1461947

Delgado-Gaitan, Concha. (1987). Traditions and transitions in the learning process of Mexican children: An ethnographic view. In George Spindler \& Louise Spindler (Eds.), Interpretive ethnography of education at home and abroad (pp. 333-362). Lawrence Erlbaum Associates.

Eisner, E. W. (1994). The educational imagination: On the design and evaluation of school programs $\left(3^{\text {rd }}\right.$ ed.). Macmillan.

Galvan, J. L., \& Galvan, M. C. (2017). Writing literature reviews: A guide for students of the social and behavioral sciences $\left(7^{\text {th }} \mathrm{ed}\right.$.). Routledge.

Garfield, J. L., Peterson, C. C., \& Perry, T. (2001). Social cognition, language acquisition and the development of the theory of mind. Mind \& Language, 16(5), 494-541. https://doi.org/10.1111/1468-0017.00180 
Garwood, J. D., \& Van Loan, C. L. (2019). Using social stories with students with social, emotional, and behavioral disabilities: The promise and the perils. Exceptionality, 27(2), 133-148. https://doi.org/10.1080/09362835.2017.1409118

Golzari, F., Hemati Alamdarloo, G., \& Moradi, S. (2015). The effect of a social stories intervention on the social skills of male students with autism spectrum disorder. Sage Open, 5(4), 1-8. https://doi.org/10.1177/2158244015621599

Gray, C. A. (n.d.). Comparison of Social Stories ${ }^{\mathrm{TM}}$ 10.0-10.2 Criteria. Retrieved from https://carolgraysocialstories.com/social-stories/what-is-it/

Gray, C. A., \& Garand, J. D. (1993). Social stories: Improving responses of students with autism with accurate social information. Focus on Autistic Behavior, 8(1), 1-10. https://doi.org/10.1177/108835769300800101

Haney, J. L. (2016). Autism, females, and the DSM-5: Gender bias in autism diagnosis. Social Work in Mental Health, 14(4), 396-407. https://doi.org/10.1080/15332985.2015.1031858

Hanrahan, R., Smith, E., Johnson, H., Constantin, A., \& Brosnan, M. (2020). A pilot randomised control trial of digitally-mediated social stories for children on the autism spectrum. Journal of Autism and Developmental Disorders. https://doi.org/10.1007/s10803-020-04490-8

Heath, S. B. (1982). What no bedtime story means: Narrative skills at home and school. Language in Society, 11(1), 49-76.

Heath, S. B. (1983). Ways with words: Language, life and work in communities and classrooms. Cambridge University Press.

Hsu, J. (2008). The secrets of storytelling. Scientific American Mind, 19(4), 46-51. https://doi.org/10.1038/scientificamericanmind0808-46

Karal, M. A., \& Wolfe, P. S. (2018). Social story effectiveness on social interaction for students with autism: A review of the literature. Education and Training in Autism and Developmental Disabilities, 53(1), 44-58. Retrieved from http://daddcec.org/Portals/0/CEC/Autism_Disabilities/Research/Publications/Education_ Training_Development_Disabilities/Full_Journals/Karal.PDF

Kassardjian, A., Leaf, J. B., Ravid, D., Leaf, J. A., Alcalay, A., Dale, S., Tsuji, K., Taubmann, M., Leaf, R., McEachin, J., \& Oppenheim-Leaf, M. L. (2014). Comparing the teaching interaction procedure to social stories: A replication study. Journal of Autism and Developmental Disorders, 44(9), 2329-40. https://doi.org/10.1007/s10803-014-2103-0

Kokina, A., \& Kern, L. (2010). Social story ${ }^{\mathrm{TM}}$ interventions for students with autism spectrum disorders: A meta-analysis. Journal of Autism and Developmental Disorders, 40(7), 812-26. https://doi.org/10.1007/s10803-009-0931-0

Lawrence, R. L., \& Paige, D. S. (2016). What our ancestors knew: Teaching and learning 
through storytelling. New Directions for Adult and Continuing Education, 2016(149), 63-72. https://doi.org/10.1002/ace.20177

Leaf, J. B., Mitchell, E., Townley-Cochran, D., McEachin, J., Taubman, M., \& Leaf, R. (2016). Comparing social stories ${ }^{\mathrm{TM}}$ to cool versus not cool. Education and Treatment of Children, 39(2), 173-185. https://doi.org/10.1353/etc.2016.0006

Leaf, J. B., Oppenheim-Leaf, M. L., Leaf, R. B., Taubman, M., McEachin, J., Parker, T., Waks, A. B., \& Mountjoy, T. (2015). What is the proof? A methodological review of studies that have utilized social stories. Education and Training in Autism and Developmental Disabilities, 50(2), 127-141.

Loomes, R., Hull, L., \& Mandy, W. P. L. (2017). What is the male-to-female ratio in autism spectrum disorder? A systematic review and meta-analysis. Journal of the American Academy of Child \& Adolescent Psychiatry, 56(6), 466-474. https://doi.org/10.1016/j.jaac.2017.03.013

Malmberg, D. B., Charlop, M. H., \& Gershfeld, S. J. (2015). A two experiment treatment comparison study: Teaching social skills to children with autism spectrum disorder. Journal of Developmental and Physical Disabilities, 27(3), 375-392. https://doi.org/10.1007/s10882-015-9420-x

Matheis, M., Matson, J. L., Hong, E., \& Cervantes, P. E. (2019). Gender differences and similarities: Autism symptomatology and developmental functioning in young children. Journal of Autism and Developmental Disorders, 49(3), 1219-1231. https://doi.org/10.1007/s10803-018-3819-z

Matthew, J. M., Shaw, K. A., Baio, J., Washington, A., Patrick, M., DiRienzo, M., Christensen, D. L., Wiggins, L. D., Pettygrave, S., Andrews, J. G., Lopez, M., Hudson, A., Baroud, T., Schwenk, Y., White, T., Rosenberg, C. R., Lee, L. C., Harrington, R. A., Huston, M., ... Dietz, P. M. (2020). Prevalence of autism spectrum disorder among children aged 8 years - Autism and developmental disabilities monitoring network, 11 sites, United States, 2016. Surveillance Summaries, 69(4), 1-12. https://doi.org/10.15585/mmwr.ss6904a1

National Autism Center. (2015). Findings and conclusions: National standards project, phase 2. Addressing the need for evidence-based practice guidelines for autism spectrum disorder. https://www.nationalautismcenter.org/090605-2/

Ogbu, J. (1982). Cultural discontinuity and schooling. Anthropology and Education Quarterly, 13(4), 290-307.

Ozuna, J., Mavridis, A., \& Hott, B. L. (2015). Interventions to support social interaction in children with autism spectrum disorders: A systematic review of single case studies. Exceptionality Education International, 25(2), 107-125.

Stephens, G. J., Silbert, L. J., Hasson, U., \& Gross, C. G. (2010). Speaker-listener neural coupling underlies successful communication. Proceedings of the National Academy of 
Sciences of the United States of America, 107(32), 14425-14430. https://doi.org/10.1073/pnas.1008662107

Suina, J. H., \& Laura, B. S. (1994). From natal culture to school culture to dominant society culture: Supporting transitions for Pueblo Indian students. In P. M. Greenfield \& R. R. Cocking (Eds.), Cross-cultural roots of minority child development (pp. 115-130). Lawrence Erlbaum Associates.

Underwood, P. (2002). Three native American learning stories: Who speaks for wolf, winter white and summer gold, many circles, many paths and containing additional information about the nature of a learning story. A Tribe of Two Press.

Windchief, S., \& Timothy S. P. (2019). Applying Indigenous research methods: Storying with peoples and communities. In Eve Tuck \& K. Wayne Yang (Series Eds.), Indigenous and decolonizing studies in education. Routledge.

\section{Copyright Disclaimer}

Copyright for this article is retained by the author(s), with first publication rights granted to the journal.

This is an open-access article distributed under the terms and conditions of the Creative Commons Attribution license (http://creativecommons.org/licenses/by/3.0/). 